\title{
Texture Formation through Thermomechanical Treatment and Its Effect on Superelasticity in Mg-Sc Shape Memory Alloy*1
}

\author{
Keisuke Yamagishi ${ }^{1, * 2}$, Daisuke Ando ${ }^{1}$, Yuji Sutou ${ }^{1}$ and Yukiko Ogawa ${ }^{2}$ \\ ${ }^{1}$ Department of Materials Science, Graduate School of Engineering, Tohoku University, Sendai 980-8579, Japan \\ ${ }^{2}$ Research Center for Structural Materials, National Institute for Materials Science, Tsukuba 305-0047, Japan
}

\begin{abstract}
The formation of texture through thermomechanical treatment was investigated in $\mathrm{Mg}-18.8$ at\% Sc shape memory alloy to enhance its superelasticity at room temperature. The samples were cold rolled in an $\alpha$ phase or in a $\beta$ phase and then finally heat treated at $690^{\circ} \mathrm{C}$ followed by water quenching to obtain a $\beta$ phase. In the case of cold rolling in the $\alpha$ phase, a basal-plane texture was formed, while no preferential texture was observed along in-plane direction. After the final heat treatment, $\{011\}\langle\mathrm{uvw}\rangle_{\beta}$ transformation texture was obtained, according to Burgers relationship, indicating no improvement of the superelasticity along in-plane direction. In the case of the cold rolling in the $\beta$ phase, a weak $\{111\}\langle 011\rangle_{\beta}$ recrystallization texture was obtained. The sample showed about $0.65 \%$ superelastic tensile strain along rolling direction, while that along transverse direction $(/ / \sim\langle 113\rangle \beta)$ showed only about $0.43 \%$. This trend is in good agreement with the orientation dependence of the transformation strain, but, the obtained superelastic strain was much lower than the expected value, which is due to the weak texture and suggests the existence of a strong grain constraint in the Mg-Sc shape memory alloy. [doi:10.2320/matertrans.MT-M2020244]
\end{abstract}

(Received July 28, 2020; Accepted September 24, 2020; Published October 30, 2020)

Keywords: bcc-magnesium alloy, texture, superelasticity

\section{Introduction}

Magnesium alloys have great potential as structural materials for automobile components and computers cases, among others, because of its lightweight and high specific strength. Moreover, the biocompatibility of $\mathrm{Mg}$ alloys indicates they could be used as core materials for medical devices. $\mathrm{Mg}$ alloys, however, show poor plastic workability at room temperature due to their anisotropic crystal structure, i.e., hexagonal close-packed (hcp) structure. To improve their workability, $\mathrm{Mg}-\mathrm{Li}$ alloys, which have an isotropic bodycentered cubic (bcc) structure, have been widely investigated. $\mathrm{Mg}-\mathrm{Li}$ binary alloys with a $\mathrm{Li}$ content of more than 12.5 mass \% have a bcc-single phase and show an excellent tensile elongation. ${ }^{1)}$ Unfortunately, these alloys have low tensile strength and poor corrosion resistance. ${ }^{1,2)}$ Moreover, these characteristics cannot be improved by microstructure control through heat treatment, as in Ti alloys, because the boundaries between the hcp $(\alpha) / \alpha+\operatorname{bcc}(\beta)$ and $\alpha+\beta / \beta$ phases is almost perpendicular to the composition axis in the phase diagram.

Our research group has focused on $\mathrm{Mg}-\mathrm{Sc}$ binary alloys, which are the only other Mg-based alloys with a bcc structure in the $\mathrm{Mg}$-rich region. $\mathrm{Mg}-\mathrm{Sc}$ alloys show a phase transformation between a low temperature $\alpha$ phase and high temperature $\beta$ phase in the $\mathrm{Mg}$-rich region when changing the heat treatment conditions, similar to Ti alloys. The two-phase alloy heat treated in the $\alpha+\beta$ region shows a high ultimate tensile strength of over $300 \mathrm{MPa}$ with an elongation of approximately 29\%.3) The $\beta$ single-phase alloy also shows excellent mechanical properties; tensile strength of over $250 \mathrm{MPa}$ and elongation of $25 \%$. $^{3)}$ In addition, it has been reported that $\mathrm{Ti}$ alloys with appropriate alloying elements show a thermoelastic martensitic transformation from a

\footnotetext{
${ }^{* 1}$ This Paper was Originally Published in Japanese in J. Japan Inst. Met. Mater. 84 (2020) 253-259.

${ }^{* 2}$ Graduate Student, Tohoku University
}

metastable bcc phase to an $\alpha^{\prime \prime}$ phase (orthorhombic structure) and exhibit shape memory effect and/or superelasticity. ${ }^{4-6)}$ Our research group found that $\mathrm{Mg}-\mathrm{Sc}$ alloys also show the thermoelastic martensitic transformation between bcc and orthorhombic structures and exhibit shape memory effect and/or superelasticity. ${ }^{7)}$ Furthermore, we recently reported that the alloys show superelasticity even at room temperature when optimizing the Sc content. ${ }^{8)}$ Similar to $\mathrm{Cu}-$ and $\mathrm{Fe}$ based shape memory alloys, ${ }^{9-11)}$ the superelastic strain can be largely improved by increasing the relative grain size $d / t$ ( $d=$ average grain size, $t=$ sample thickness) owing to the decrease in grain constraint from the surrounding grains. ${ }^{8)} \mathrm{A}$ sample with a grain size of $\sim 5 \mathrm{~mm}$ shows a superelastic strain of approximately $3 \%$ at room temperature. ${ }^{8)}$

Texture formation is a different way to improve superelastic properties. For example, a strong recrystallization texture in which the $\langle 011\rangle$ direction is parallel to the rolling direction is obtained in Ti-based shape memory alloys after heavy cold rolling (thickness reduction of 99\%) in a $\beta$-single phase and subsequent solution treatment at the $\beta$ single phase temperature. ${ }^{12,13)}$ Based on phenomenological calculations, Ti-based shape memory alloys are known to show a maximum superelastic strain along the $\langle 011\rangle$ direction; therefore, polycrystalline alloys with strong recrystallization texture may present excellent superelastic properties. ${ }^{13,14)}$ However, to the best of our knowledge, there are no reports on the recrystallization texture of $\mathrm{Mg}-\mathrm{Sc}$ alloys. Moreover, in addition to the recrystallization texture, the transformation texture, which is acquired from the deformation texture, has been investigated in controlledrolled steels and ausformed steels based on the orientation relationship during the transformation. ${ }^{15,16)}$ It is well known that $\mathrm{Mg}$ alloys with an $\alpha$ phase show a basal texture after deformation. ${ }^{17,18)}$ Also, it has been reported that the $\alpha$ phase in the $\mathrm{Mg}-\mathrm{Sc} \alpha+\beta$-two phase alloy shows a basal texture after cold-rolling. ${ }^{19)}$ Therefore, the basal texture in the $\alpha$ phase formed by cold rolling is expected to result in a $\beta$ transformation texture in $\mathrm{Mg}-\mathrm{Sc}$ alloys. In this study, we 
investigated the formation of texture in the $\beta$ phase of a $\mathrm{Mg}-\mathrm{Sc}$ alloy and analyzed the effect of the texture on the superelastic properties of the alloy at room temperature.

\section{Experimental Procedures}

\subsection{Sample preparation}

A Mg-Sc alloy ingot was obtained from OSTECH Co. Ltd. and Hunan Oriental Scandium Co. Ltd. The average composition ( $\mathrm{Mg}-18.8$ at\% $\mathrm{Sc}$ ) was determined using an electron probe micro analyzer (EPMA). Blocks with a thicknesses of about $15 \mathrm{~mm}$ were cut from the ingot and hot rolled at $650^{\circ} \mathrm{C}$ down to $5 \mathrm{~mm}$. The rolled samples were homogenized at $600^{\circ} \mathrm{C}$ for $24 \mathrm{~h}$, then treated as described in section 2.2 to achieve texture.

\subsection{Thermomechanical treatments}

\subsubsection{Cold rolling in $\alpha$-single phase}

The homogenized samples were solution treated at $690^{\circ} \mathrm{C}$ for $30 \mathrm{~min}$ followed by quenching into iced water to obtain a $\beta$-single phase. The samples were then heat treated at $500^{\circ} \mathrm{C}$ for $2 \mathrm{~h}$ and quenched to obtain an $\alpha$-single phase. It is worth noting that the solution treatment at the $\beta$-single phase temperature can randomize the texture in the $\alpha$ phase. ${ }^{19)}$ The thermomechanical treatments (TMP 1-3) listed below were conducted for the obtained $\alpha$-single phase sample, Fig. 1(a)(c). The thickness reduction per pass was set to about $2 \%$.

TMP 1: cold rolling, total thickness reduction of $40 \%$, no intermediate annealing.

(a) TMP1

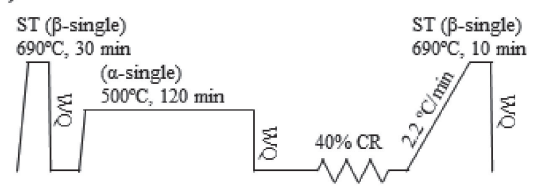

(b) TMP2

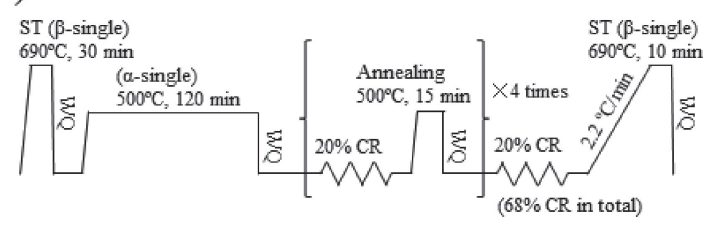

(c) TMP3

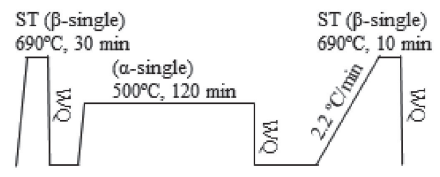

(d) TMP4

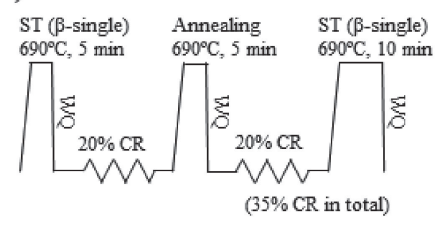

Fig. 1 Schematic diagrams of the thermomechanical processes (TMP), (a) TMP1, (b) TMP2, (c) TMP3, and (d) TMP4. ST, WQ and CR indicate solution treatment at $\beta$-single phase temperature range, water quenching and cold rolling, respectively.
TMP 2: cold rolling, total thickness reduction of $68 \%$, intermediate annealing at $500^{\circ} \mathrm{C}$ for $15 \mathrm{~min}$ (repetition of cold rolling to $20 \%$ thickness reduction and annealing for 4 times)

TMP 3: no cold rolling.

Finally, the samples were solution treated at $690^{\circ} \mathrm{C}$ for $30 \mathrm{~min}$ and quenched into iced water to obtain a $\beta$-single phase. When heating from room temperature to $690^{\circ} \mathrm{C}$, the rate was set to $2.2^{\circ} \mathrm{C} / \mathrm{min}(5 \mathrm{~h})$ to allow for complete recrystallization in the $\alpha$-single phase temperature region first, then the recrystallized $\alpha$-single phase would transform into the $\beta$ single phase. The heating rate should be slow because, for example, it takes only $10 \mathrm{~min}$ at $500^{\circ} \mathrm{C}$ to recrystallize the $\alpha$-single phase sample after $40 \%$ cold rolling.

\subsubsection{Cold rolling in $\boldsymbol{\beta}$-single phase}

The homogenized samples were solution treated at $690^{\circ} \mathrm{C}$ for $5 \mathrm{~min}$ and quenched into iced water to obtain a $\beta$-single phase. The thermomechanical treatment TMP 4 was conducted for these samples, Fig. 1(d), in which the thickness reduction per pass was set to about $2 \%$.

TMP 4: cold rolling, total thickness reduction of $35 \%$, intermediate annealing at $690^{\circ} \mathrm{C}$ for $5 \mathrm{~min}$ (cold rolling to $20 \%$ thickness reduction followed by annealing, then further cold rolling to $20 \%$ thickness reduction).

Finally, the samples were solution treated at $690^{\circ} \mathrm{C}$ for $10 \mathrm{~min}$ and quenched into iced water to obtain a $\beta$-single phase. The $\mathrm{Mg}-\mathrm{Sc}$ alloy with the $\beta$-single phase had a relatively large grain size $(\sim 150 \mu \mathrm{m})$, causing intergranular fractures during cold rolling. In addition, the maximum thickness reduction was $\sim 35 \%$ in total.

\subsection{Texture characterization}

The texture of the samples was analyzed by electron backscatter diffraction (EBSD). Prior to the EBSD measurement, the sample surface was mechanically polished with $\mathrm{SiC}$ papers and diamond pastes of different grits, and then chemically etched to obtain a mirror-like surface. The step size and scan area were respectively $2 \mu \mathrm{m}$ and $\sim 450 \times$ $1300 \mu \mathrm{m}$ in the $\alpha$-single phase sample (grain size $\sim 25 \mu \mathrm{m}$ ), and $4 \mu \mathrm{m}$ and $\sim 900 \times 2600 \mu \mathrm{m}$ in the $\beta$-single phase sample (grain size $\sim 150 \mu \mathrm{m}$ ). EBSD was conducted in two different areas in each sample. Pole figures (PFs) and inverse pole figures (IPFs) for each sample were obtained from the average of the two areas.

\subsection{Superelasticity}

Cyclic loading-unloading tensile tests were conducted at room temperature to investigate superelasticity (strain rate $=$ $10^{-3} \mathrm{~s}^{-1}$ ). The sample was loaded until the strain reached $\mathrm{N} \%$ and unloaded down to zero stress in the $\mathrm{N}^{\text {th }}$ cycle $(\mathrm{N}=$ $1,2,3, \ldots)$. The loading-unloading cycle was repeated until the applied strain reached 5\%. The width, thickness, and gauge length of the samples were $4,0.5$, and $15 \mathrm{~mm}$, respectively.

\section{Results and Discussion}

\subsection{Transformation texture}

Figure 2 shows IPF maps in normal direction (ND) and 
(a)

(b)
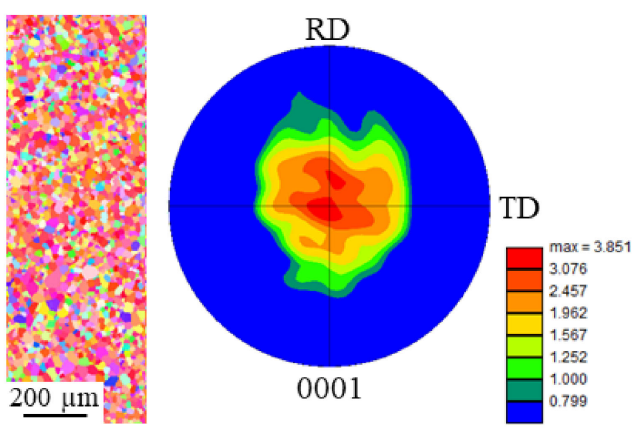

(c)
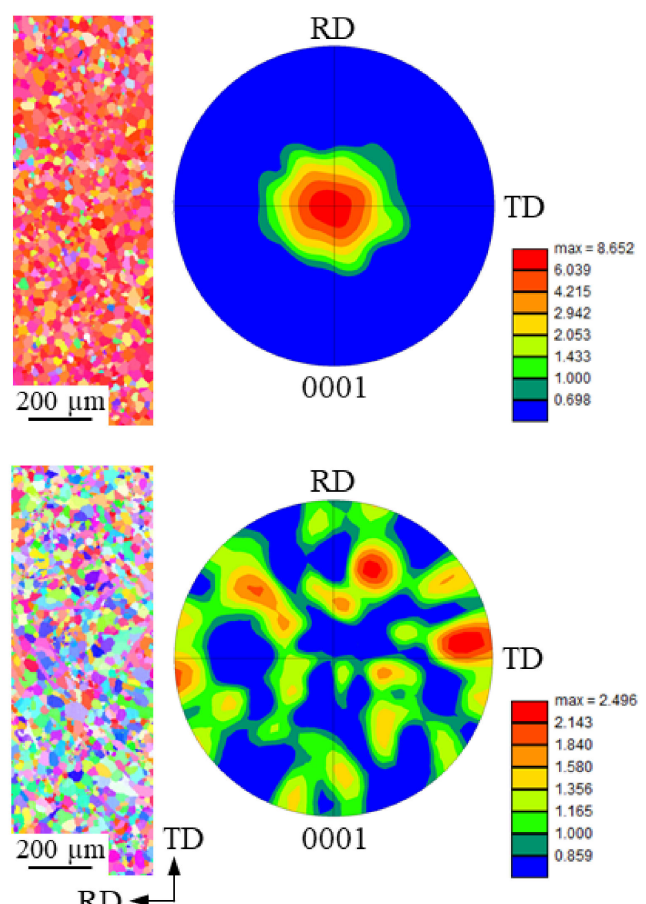

$\mathrm{RD} \leftarrow$

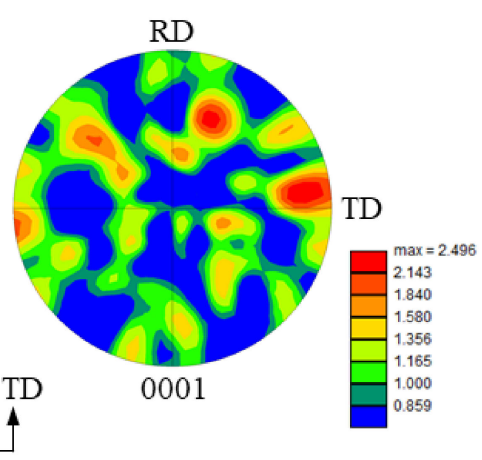

(d)

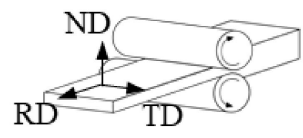

(e)

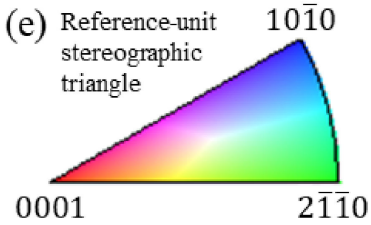

Fig. 2 IPF maps and $(0001)_{\alpha}$ pole figures of the $\alpha$-phase samples, (a) after $40 \%$ cold rolling in TMP 1 followed by annealing at $500^{\circ} \mathrm{C}$ for $15 \mathrm{~min}$, (b) after $68 \%$ total cold rolling in TMP 2 followed by annealing at $500^{\circ} \mathrm{C}$ for $15 \mathrm{~min}$, and (c) no cold rolling (TMP 3). (d) The reference directions in a rolled sheet and (e) the reference-unit stereographic triangle.

(0001) PFs obtained from the $\alpha$-single phase sample after cold rolling to a total thickness reduction of $40 \%$ and $68 \%$. To achieve a high image quality (IQ) value, the samples were annealed at $500^{\circ} \mathrm{C}$ for $15 \mathrm{~min}$ before the EBSD measurement. The results for the $\alpha$-single phase sample with no cold rolling are shown in Fig. 2(c) for comparison. The diagram in Fig. 2(d) shows the normal (ND), rolling (RD) and transverse (TD) directions. Figure 2(e) shows the reference-unit stereographic triangle.

Figure 3 shows IPFs in the ND (top) and RD (bottom) of the samples obtained under different rolling conditions. As seen from Fig. 2(c) and Fig. 3, the $\alpha$-single phase sample before cold rolling shows a random texture, indicating that the phase transformation from $\beta$ to $\alpha$ causes the randomization of the texture, as previously reported. ${ }^{19)}$ Moreover,
Fig. 2(a) shows that the (0001) plane is likely to be parallel to the rolling plane after cold rolling to a $40 \%$ thickness reduction, which is similar to the behavior of conventional $\mathrm{Mg}$ alloys with a basal texture obtained by cold rolling. Further cold rolling, i.e., to a thickness reduction of $68 \%$, results in a stronger basal texture, Fig. 2(b). The IPFs in the $\mathrm{RD}$ (Fig. 3) also indicate that no specific texture is formed in the rolling plane.

Figure 4 shows the (a) IPF map and (b) IPF of the $\beta$-single phase sample after TMP 1 . The $\beta$-single phase sample has a transformation texture with the $\{011\}$ plane parallel to the rolling plane, Fig. 4(b). It is worth noting that the pixels with a confidence index value of 0.1 or less are shown in black in the map, Fig. 4(a). The black areas correspond to plate-like shaped martensite phases (black arrow in Fig. 4(c)) that are formed during quenching. Figure 5 shows the IPFs in the $\mathrm{ND}$ and RD of the $\beta$-single phase samples after TMP 1 , TMP 2, and TMP 3. For the TMP 1 and TMP 2 treated samples, the $\{011\}$ plane of the $\beta$ phase tends to be parallel to the rolling plane, and the tendency becomes more evident when increasing the cold rolling reduction ratio, suggesting that the transformation texture of the $\beta$ phase acquires the rolling texture formed in the $\alpha$ phase. In fact, in the sample with no cold rolling in the $\alpha$ phase (TMP 3 sample), the $\{011\}$ plane is not parallel to the rolling plane. Moreover, in the $\mathrm{RD}$, when the cold-rolling reduction ratio increases there is no clear tendency on the formation of a specific crystal orientation. The mechanism of formation of the $\beta$ phase transformation texture is explained as follows. It has been reported for $\mathrm{Mg}-\mathrm{Sc}$ alloys that an $\alpha$ phase precipitates in a $\beta$ matrix phase by aging, in accordance with the following Burgers relationship:20-22)

$$
\left([1 \overline{2} 10]_{\alpha} / /[111]_{\beta},(0002)_{\alpha} / /(\overline{1} 01)_{\beta}\right) .
$$

That is, the $\alpha$ phase with a basal texture transforms into the $\beta$ phase with the $\{011\}$ plane parallel to the rolling plane after the final solution treatment, in accordance with the Burgers relationship. In addition, the RD of the cold-rolled $\alpha$ singlephase samples have a wide orientation distribution from [10 $\overline{1} 0]$ to $[2 \overline{1} \overline{1} 0]$, as seen in Fig. 3. This indicates that no specific crystal orientation is formed in the RD regardless of the degree of thickness reduction, resulting in the randomlyoriented transformation texture of the $\beta$ phase. The results for the TMP 1-3 sample reveal that the $\beta$ phase transformation texture obtained after cold rolling in the $\alpha$ phase consists of a $\{011\}\langle\mathrm{uvw}\rangle$ type texture in which the $\{011\}$ plane is parallel to the rolling plane and the $\langle\mathrm{uvw}\rangle$ direction is oriented in the RD. This indicates that the obtained transformation texture does not enhance the superelasticity in the $\mathrm{Mg}-\mathrm{Sc}$ alloy because a random texture is formed in both the RD and TD, which must be the tensile direction in sheet samples.

\subsection{Recrystallization texture}

Figure 6 shows IPF maps and IPFs in (a) ND, (b) RD, and (c) TD obtained from the $\beta$-single phase sample after TMP 4 . The results indicate that the $\beta$-Mg-Sc alloy after cold rolling in the $\beta$ phase followed by solution treatment at the $\beta$ singlephase temperature region shows near $\{111\}\langle 011\rangle$ recrystallization texture. The RD and TD tend to orient in the $\langle 011\rangle$ and $\langle 113\rangle$ directions, respectively. The $\langle 011\rangle$ orientation in 


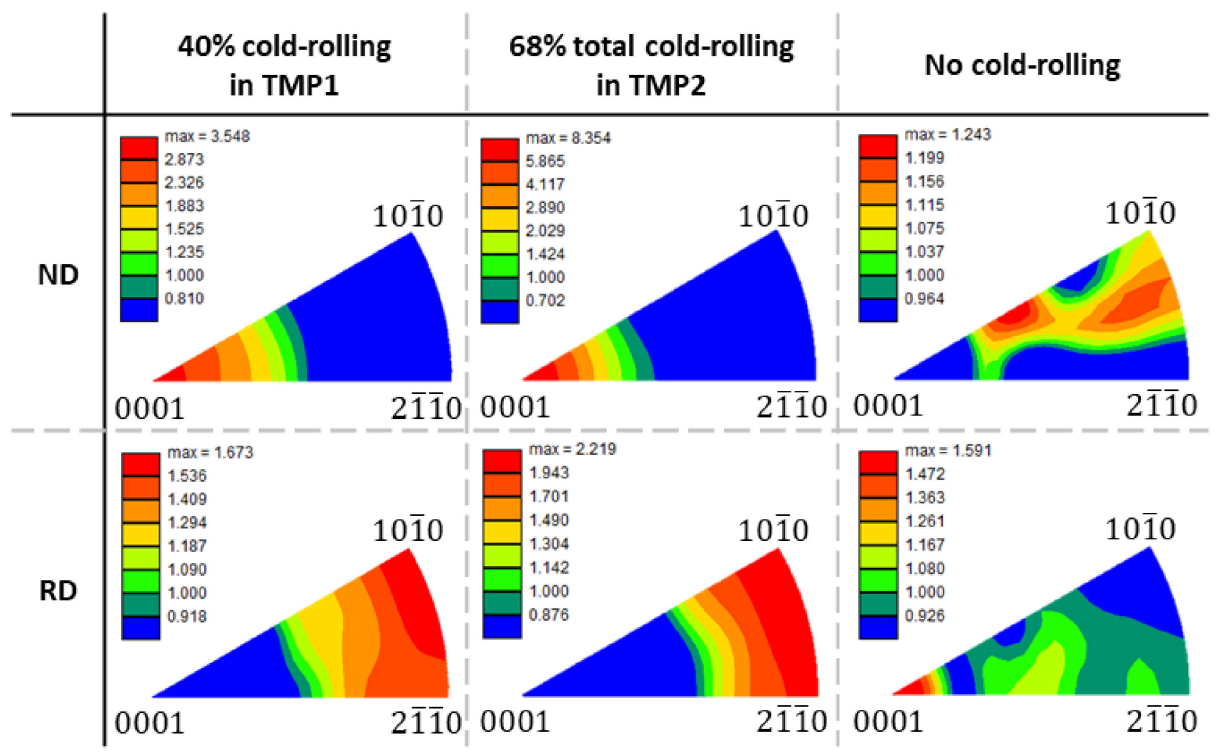

Fig. 3 Inverse pole figures of the $\alpha$-phase in ND and RD obtained after $40 \%$ cold rolling in TMP 1 followed by subsequent annealing at $500^{\circ} \mathrm{C}$ for $15 \mathrm{~min}, 68 \%$ total cold rolling in TMP 2 followed by subsequent annealing at $500^{\circ} \mathrm{C}$ for 15 min and without cold rolling (TMP 3).

(a)

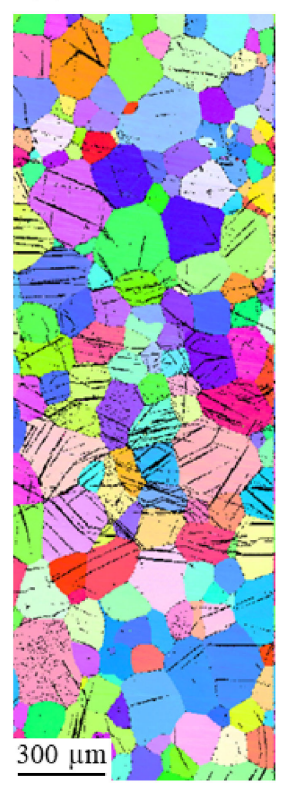

(b)

(c)
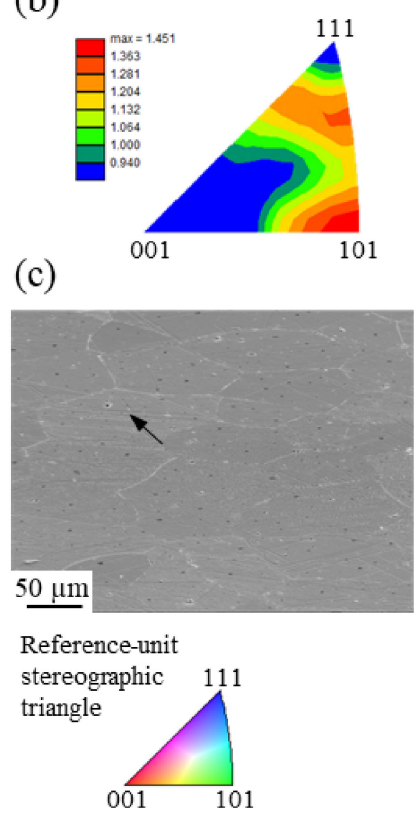

Fig. 4 (a) An IPF map and (b) an inverse pole figure in ND of the sample after TMP 1. (c) SEM image in high magnification.

the RD formed by cold rolling has also been reported in other bcc-type alloys, such as $\mathrm{Ti}-$ and $\mathrm{Cu}$-based alloys with a $\{112\}\langle 011\rangle$ recrystallization texture ${ }^{12,13,23)}$ and carbon steels with a $\{111\}\langle 011\rangle$ recrystallization texture. ${ }^{24)}$ It is known that the recrystallization texture intensity strongly depends on the cold-rolling reduction ratio, and that a strong texture can be obtained when the reduction ratio exceeds $50 \% .{ }^{12,23)}$ In the case of Ti-based alloys, the intensity of the recrystallization texture obtained after cold rolling to a $99 \%$ thickness reduction is 40 times stronger than that of the random texture. ${ }^{12)}$ As mentioned in section 2.2.2, the $\mathrm{Mg}-\mathrm{Sc}$ alloy obtained here has relatively large $\beta$ grain size that causes an intergranular fracture; limiting the thickness reduction to

about $35 \%$. Therefore, only a texture with low intensity $(\sim 2)$ can be obtained, as shown in Fig. 6. Additionally, the strains of the martensitic transformation between the bcc and orthorhombic structures in the alloy are expected to be $\sim 8.8 \%$ along the $\langle 011\rangle$ direction and $\sim 6.2 \%$ along the $\langle 113\rangle$ direction, according to the orientation dependence of the transformation strain under tensile deformation. ${ }^{25)}$ In other words, tensile testing along the RD and TD can indicate how the recrystallization texture obtained by TMP 4 affects the superelasticity.

\subsection{Superelasticity}

Figure 7(a) shows the cyclic stress-strain curves along the RD and TD obtained from sheet samples with $\beta$-single phase after TMP 4 . The $\varepsilon_{\mathrm{SE}}^{i}, \varepsilon_{\mathrm{t}}^{i}, \varepsilon_{\mathrm{r}}^{i}$, and $\varepsilon_{\mathrm{e}}^{i}$ correspond to the superelastic strain, total strain, residual strain, and elastic strain at the $i^{\text {th }}$ cycle. As seen from Fig. 7(a), the RD sample $(/ / \sim 011\rangle)$ shows lower apparent yield stress, i.e., lower stress to induce the martensite phase, than the TD sample $(/ / \sim\langle 113\rangle)$. The difference in yield stress can be explained by the difference of the texture orientation in the tensile direction. According to the Clausius-Clapeyron relationship, the stress to induce the martensitic transformation decreases with increasing transformation strain. The orientation dependence of the transformation strain in the $\beta$-Mg-Sc alloy indicates that the $\langle 011\rangle$ orientation has a larger transformation strain than the $\langle 113\rangle$ orientation. ${ }^{25)}$ This suggests that the RD sample with $\langle 011\rangle$ orientation in the tensile direction would have lower stress for the induction of the martensitic transformation than the TD sample with $\langle 113\rangle$ orientation. The dependence of yield stress on texture orientation has also been observed in $\mathrm{Ti}^{13,14,26)}$ and $\mathrm{Cu}$-based ${ }^{23)}$ shape memory alloys. In Fig. 7(b), superelastic strains were plotted as a function of the applied strain. The RD sample shows a slightly better superelasticity than the TD sample, which agrees with the orientation dependence of the transformation strain. The difference in superelastic strain between the two 


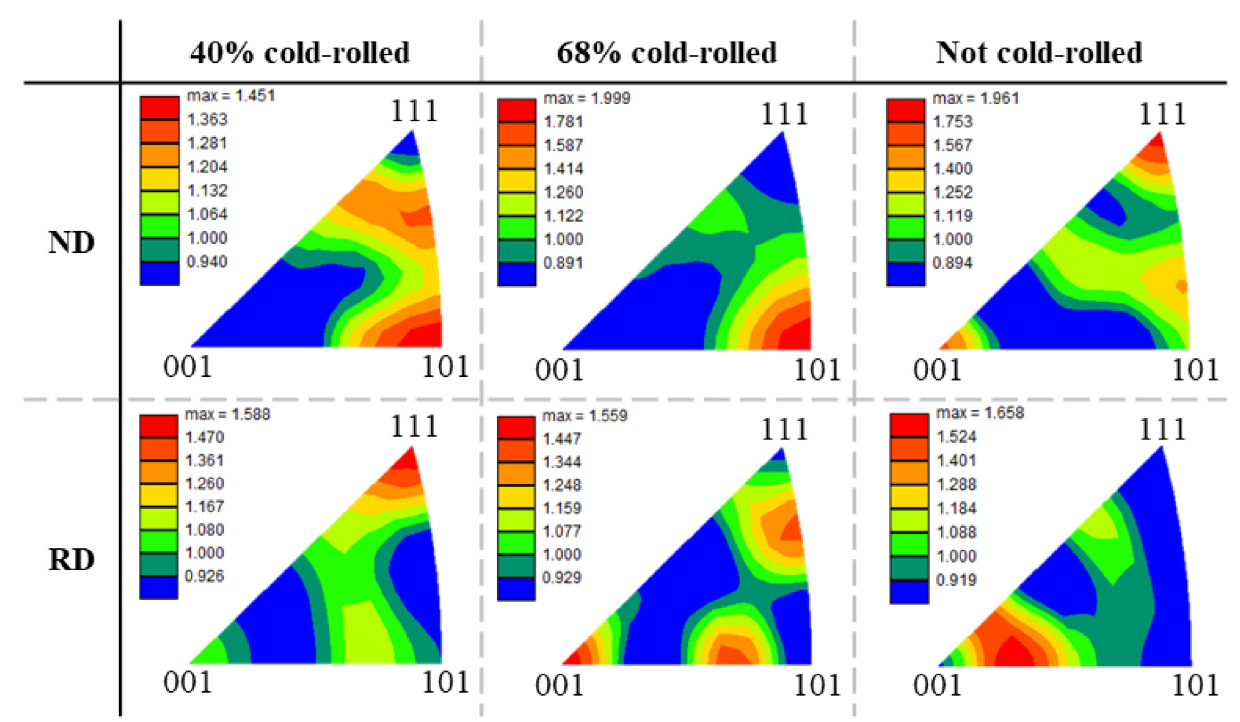

Fig. 5 Inverse pole figures of the $\beta$-phase in ND and RD obtained after $40 \%$ cold rolling in TMP 1 followed by subsequent solution treatment at $690^{\circ} \mathrm{C}$ for $10 \mathrm{~min}, 68 \%$ total cold rolling in TMP 2 followed by subsequent solution treatment at $690^{\circ} \mathrm{C}$ for $10 \mathrm{~min}$ and without cold rolling (TMP 3) followed by subsequent solution treatment at $690^{\circ} \mathrm{C}$ for $10 \mathrm{~min}$.

(a)

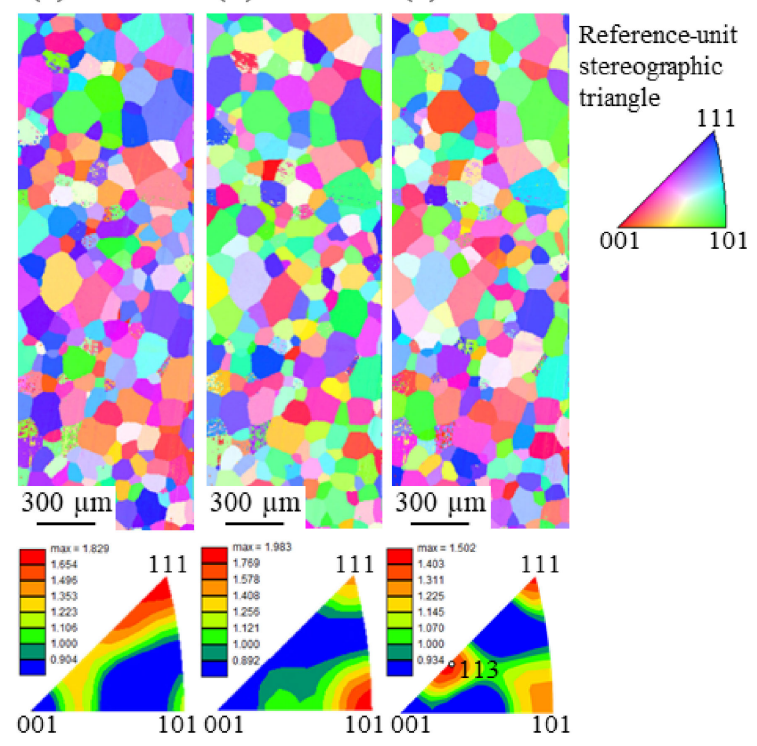

Fig. 6 IPF maps and inverse pole figures in (a) ND, (b) RD, (c) TD obtained for the $\beta$-phase after TMP 4.

samples is, however, only $0.2 \%$, and the superelastic strain obtained in the RD sample is limited to $\sim 0.65 \%$. This is due to the weak texture because of the low cold workability. The results suggest that the formation of the recrystallization texture is not very effective in enhancing the superelasticity of the $\mathrm{Mg}-\mathrm{Sc}$ alloy. To form a strong texture, it is necessary to improve the cold workability through grain refinement. The Mg-Sc alloy, however, shows a $\beta$-transus temperature of $\sim 650^{\circ} \mathrm{C}$ and a solidus temperature of $\sim 720^{\circ} \mathrm{C}$. Therefore, according to the reported phase diagram of $\mathrm{Mg}-\mathrm{Sc}$ binary alloy, the temperature window to obtain a $\beta$-single phase is very narrow. ${ }^{3,27)}$ This indicates that solution treatment at a temperature just below the melting point is required to obtain a $\beta$-single phase, causing a rapid grain growth to about $150 \mu \mathrm{m}$ even for a short-time treatment. Grain refinement by pinning effect through the addition of a third element may
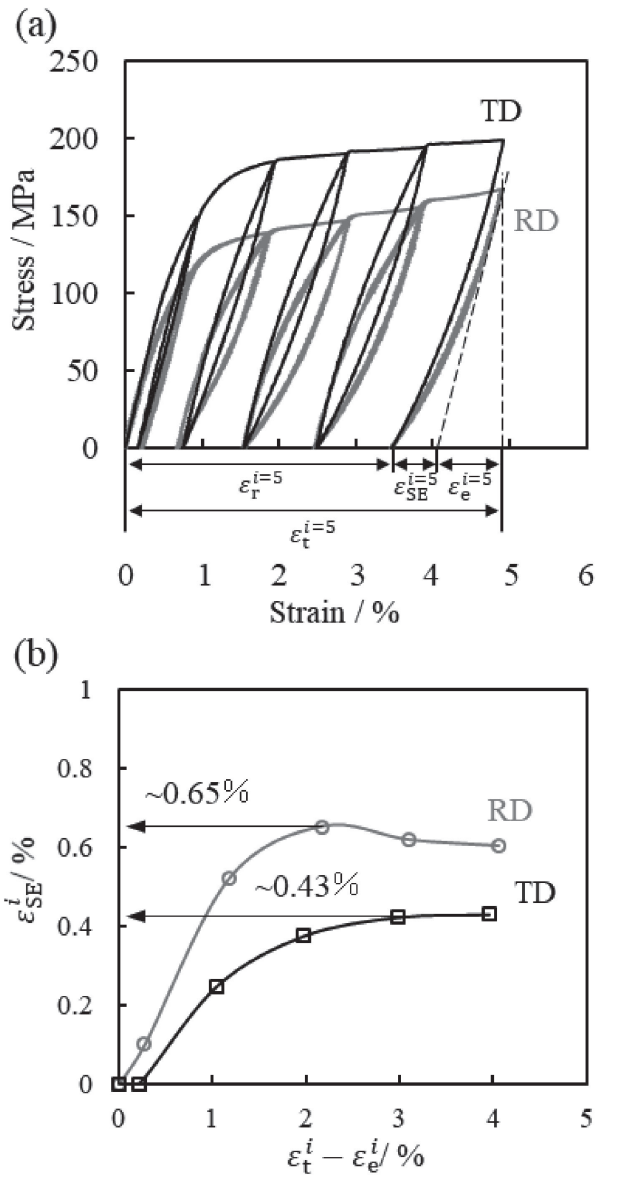

Fig. 7 (a) Cyclic tensile stress-strain curves tested along RD and TD at room temperature. (b) Plots of superelastic strain as a function of the applied strain.

improve the cold workability of the $\beta$ phase and enhance the texture development.

In addition, it is worth noting that some alloys show superior superelasticity in spite of a low texture intensity. ${ }^{23)}$ The results in this study indicate that plastic deformation is easily introduced in the $\mathrm{Mg}-\mathrm{Sc}$ alloy. Generally, the stress to 
induce a martensitic transformation is increased by the grain constraint; once the stress exceeds the critical value for slip deformation, plastic deformation is introduced and deteriorates superelasticity. ${ }^{9,10)}$ Since the Vickers hardness of the $\mathrm{Mg}-18.8$ at\% Sc alloy is just about $100 \mathrm{Hv}$, its critical stress for slip is much lower than that of other shape memory alloys, resulting in a small superelastic strain. It is therefore necessary to not only develop texture and control the grain size but also to increase the strength of the $\beta$ matrix phase by the addition of a third element to enhance the room temperature superelasticity of the $\mathrm{Mg}-\mathrm{Sc}$ binary alloy.

\section{Conclusions}

The formation of texture by thermomechanical treatment of a $\mathrm{Mg}-18.8$ at\% Sc alloy was studied. When cold rolling in the $\alpha$ single-phase, the basal texture became more evident as the thickness reduction ratio increased. When the cold-rolled samples were solution treated in the $\beta$ single-phase, the transformation texture of the $\{011\}_{\beta}$ plane parallel to the rolling plane was formed according to the Burgers relationship between the $\alpha$ and $\beta$ phases. In this case, however, no specific orientation was observed in the RD and TD in the cold-rolled $\alpha$ single-phase samples, resulting in a randomlyoriented transformation texture.

When cold rolling in the $\beta$ single-phase, a weak $\{111\}\langle 011\rangle$ recrystallization texture was obtained after a total thickness reduction of $35 \%$. The intensity of the recrystallization texture was approximately two times stronger than that of the random texture. The superelastic strain of the samples was limited to $0.65 \%$ even when the tensile direction was set to be along the $\mathrm{RD}$, in which the maximum superelastic strain was expected because of the orientation dependence of the transformation strain. This limited value is due to the low cold workability of the $\beta$ - MgSc alloy with relatively large grain size. Thus, improving the cold workability of the $\beta$ phase via grain refinement by the addition of a third element is expected to enhance the texture development and improve the superelasticity of the $\mathrm{Mg}-\mathrm{Sc}$ alloy. Moreover, the results suggest that plastic deformation is easily introduced in the $\mathrm{Mg}-\mathrm{Sc}$ binary alloy, implying that strengthening of the $\beta$ phase is also necessary to enhance the room temperature superelasticity.

\section{Acknowledgments}

This work was supported by JSPS KAKENHI Grant
Numbers (17J10094, 18K14032, 18H01691) and Adaptable and Seamless Technology transfer Program through Targetdriven R\&D (A-STEP) from Japan Science and Technology Agency (JST).

\section{REFERENCES}

1) H.T. Son, Y.H. Kim, D.W. Kim, J.H. Kim and H.S. Yu: J. Alloy. Compd. 564 (2013) 130-137.

2) C. Zhang, X. Huang, M. Zhang, L. Gao and R. Wu: Mater. Lett. 62 (2008) 2177-2180.

3) Y. Ogawa, D. Ando, Y. Sutou, K. Yoshimi and J. Koike: Mater. Sci. Eng. A 670 (2016) 335-341.

4) K. Endoh, M. Tahara, T. Inamura and H. Hosoda: Mater. Sci. Eng. A 704 (2017) 72-76.

5) H.Y. Kim and S. Miyazaki: Mater. Trans. 56 (2015) 625-634.

6) J. Fu, A. Yamamoto, H.Y. Kim, H. Hosoda and S. Miyazaki: Acta Biomater. 17 (2015) 56-67.

7) Y. Ogawa, D. Ando, Y. Sutou and J. Koike: Science 353 (2016) 368370 .

8) K. Yamagishi, Y. Ogawa, D. Ando, Y. Sutou and J. Koike: Scr. Mater. 168 (2019) 114-118

9) Y. Sutou, T. Omori, K. Yamauchi, N. Ono, R. Kainuma and K. Ishida: Acta Mater. 53 (2005) 4121-4133.

10) Y. Sutou, T. Omori, R. Kainuma and K. Ishida: Acta Mater. 61 (2013) 3842-3850.

11) T. Omori, M. Okano and R. Kainuma: APL Mater. 1 (2013) 032103.

12) T. Inamura, R. Shimizu, H.Y. Kim, S. Miyazaki and H. Hosoda: Mater. Sci. Eng. C 61 (2016) 499-505.

13) H.Y. Kim, T. Sasaki, K. Okutsu, J.I. Kim, T. Inamura, H. Hosoda and S. Miyazaki: Acta Mater. 54 (2006) 423-433.

14) Y. Fukui, T. Inamura, H. Hosoda, K. Wakashima and S. Miyazaki: Mater. Trans. 45 (2004) 1077-1082.

15) R.K. Ray and J.J. Jonas: Int. Mater. Rev. 35 (1990) 1-36.

16) T. Yutori and R. Ogawa: Tetsu-to-Hagané 65 (1979) 1747-1755.

17) S.H. Park, S.G. Hong and C.S. Lee: Mater. Sci. Eng. A 578 (2013) 271-276.

18) M.Z. Bian, A. Tripathi, H. Yu, N.D. Nam and L.M. Yan: Mater. Sci. Eng. A 639 (2015) 320-326.

19) Y. Ogawa, D. Ando, Y. Sutou and J. Koike: Scr. Mater. 128 (2017) 2731.

20) W.G. Burgers: Physica 1 (1934) 561-586.

21) D. Ando, Y. Ogawa, T. Suzuki, Y. Sutou and J. Koike: Mater. Lett. 161 (2015) 5-8.

22) Y. Ogawa, D. Ando, Y. Sutou and J. Koike: Mater. Trans. 57 (2016) 1119-1123.

23) Y. Sutou, T. Omori, R. Kainuma, N. Ono and K. Ishida: Metall. Mater. Trans. A 33 (2002) 2817-2824.

24) M. Takahashi and A. Okamoto: Tetsu-to-Hagané 61 (1975) 2246-2262.

25) Y. Ogawa, D. Ando, Y. Sutou, H. Somekawa and J. Koike: Shap. Mem. Superelasticity 4 (2018) 167-173.

26) H. Hosoda, Y. Kinoshita, Y. Fukui, T. Inamura, K. Wakashima, H.Y. Kim and S. Miyazaki: Mater. Sci. Eng. A 438-440 (2006) 870-874.

27) B.J. Beaudry and A.H. Daane: J. Less Common Met. 18 (1969) 305308 . 